\title{
Failure Characteristics and Stability Control of Roadway Surrounding Rocks under Different Lateral Pressure Coefficients
}

\author{
Zhiyu Chen ${ }^{1}$, Zhiqiang Yin ${ }^{1,2, *}$, Jucai Chang ${ }^{1}$, Wenbao Shi ${ }^{1}$ and Xingqiu Peng ${ }^{2}$ \\ ${ }^{1}$ Key Laboratory of Safe and Effective Coal Mining, Ministry of Education, Anhui University of Science and Technology, Huainan \\ 232001, China \\ ${ }^{2}$ Centre for Infrastructural Monitoring and Protection, School of Civil and Mechanical Engineering, Curtin University, WA 6102, \\ Australia \\ ${ }^{3}$ National Engineering Research Center for Coal Gas Control, Huainan, Anhui 232001, China
}

Received 2 April 2020; Accepted 7 October 2020

\begin{abstract}
The stability control of mining roadways is crucial in ensuring the safe and efficient mining of deep coal resources. Given the effect of mining stress on the working face, the support scheme of such roadways, which is designed based on the original in-situ stress parameters, often presents support-related problems. A mining roadway on the 1131 working face of Zhujidong Coal Mine in the Huainan mining area, China was taken as the engineering background of this study. To explore the influence of mining stress on the stability control of this roadway, the 2-dimensional (2D) Particle Flow Code (PFC) numerical simulation software was used to perform a simulation study on the stress distribution characteristics and deformation failure laws of the surrounding rocks under the change in the roadway lateral pressure coefficient caused by the mining stress. An improved support scheme that considers the influence of varying lateral pressure coefficient on the mining roadway was then proposed. Results show that when the lateral pressure coefficient increased from 1 to 1.4 , the maximum principal stress $(61.2 \mathrm{MPa})$ is observed at $2.9 \mathrm{~m}$ inside the roof of the surrounding rocks in the roadway. When the lateral pressure coefficient decreases from 1 to 0.4 , the maximum principal stress $(46.2 \mathrm{MPa})$ is observed at $2.2 \mathrm{~m}$ inside the surrounding rock of sidewalls of the roadway, and failure occurs. These findings suggest that the deformation and failure of surrounding rocks are affected regardless of the lateral pressure coefficient increase or decrease. On this basis, the lengths of the anchor bolts in the roof and sidewalls in the original support method are increased from 2,200 $\mathrm{mm}$ to $3,000 \mathrm{~mm}$ and $2,500 \mathrm{~mm}$, respectively. The field monitoring results indicate that the improved support method mitigates the deformation and realizes the stability control of the roadway surrounding rocks. The findings of this study could provide a scientific basis for the parameter design of roadway support.
\end{abstract}

Keywords: Lateral pressure coefficient, PFC, Mining roadway, Principal stress, Supporting

\section{Introduction}

Bolt support is the main support method of the surrounding rocks in coal mine roadways. At present, nearly $10,000 \mathrm{~km}$ of roadways are supported by bolts in the newly excavated roadway engineering of Chinese coal mines every year. In terms of pre-stress, anchor bolts form a stress-carrying structure with the surrounding rock, which resists the static ground stress around the roadway by utilizing their selfcarrying capacity and results in the active support of the roadway $[1,2]$. However, the stress field around the roadway near the working face changed due to the influence of mining work [3]. In most cases, only the original in-situ stress is used when designing the roadway bolt parameters. As a result, the supporting intensity may be insufficient, which will lead to the large deformation of the roadway surrounding rocks and cause hidden perils to safe and efficient coal mining. Therefore, realizing the stability control of the surrounding rocks in mining roadways under mining stress is important in achieving stable roadway support and safe mining in the working faces of deep mines.

Previous studies on the deformation failure characteristics of mining roadways emphasized the

\footnotetext{
E-moil address: zhquin@oust.edu.cn

ISSN: $1791-2377$ @ 2020 School of Science, IHU. All rights reserved.

doi:10.25103/iestr.135.06
}

mechanical properties and support structure of the roadway surrounding rocks. Various theories that define roadway crushing and plastic deformation characteristics (e.g., the theory of surrounding rock loose circle [4] and theory of plastic zone [5]) were proposed, along with related supporting theories based on the features of the supporting body [6]. Field monitoring and numerical simulation manifest that mining roadways undergo an obvious change in the surrounding rock stress field during the mining process, which consequently increases and then decreases the lateral pressure coefficient [7,8]. According to related research, the stress distribution pattern of the roadway determines the rupture position of the surrounding rock [9]. Therefore, investigating the influence of the variation in lateral pressure coefficient triggered by mining disturbance on the surrounding rock stability in mining roadways is important in improving roadway support parameters and increasing the surrounding rock control efficiency.

On basis of the above discussion, this study takes a mining roadway on the 1131 working face of Zhujidong Coal Mine in Huainan mining area, China as the engineering background to analyze the mechanical characteristics and fracturing behaviors of the rectangular roadway under different lateral pressure coefficients through numerical simulation. This work lays an experimental foundation for 
the further investigation of surrounding rock control under mining disturbance.

\section{State of the art}

To adapt to the high-intensity mining of coal resources, many mining roadways utilize rectangular cross-sections. However, the deformation and failure characteristics of these roadways greatly differ from those of other shapes and are mainly manifested by poor surrounding rock stability. The deformation and failure characteristics of rectangular roadways are studied by many researchers to reduce the number of instability accidents caused by deformation failure. Frith et al. [10] investigated the support properties of layered roof roadways by grouting bolts, which is a method that coordinates bolt pretension and grouting pressure. This technique can increase the load capacity and realize the stability of the roadway roof. By considering the New Shanghai Mine in Inner Mongolia as the study area, Li [11] simulated the deformation failure of a rectangular roadway by using the Cvisc viscoelastic-plastic model in FLAC3D and analyzing the stress distribution and surrounding rock crack form. Gong et al. [12] simulated the failure phenomenon on the side wall of rectangular tunnels under different lateral pressures by using a true triaxial compression testing machine and cubic specimens prefabricated with rectangular holes. They then proposed a support method for reducing the failure degree. The abovementioned studies mainly focused on the mechanical and deformation failure characteristics of rectangular roadways under a certain stress state. However, as the practical field experience continuously develops, researchers realize that the stress field of the roadways during the mining process is not constant. Mark [13] summarized the surrounding rock instability accidents in coal mines in America and argued that the change in the stress field of such rocks causes uncertainties to their stability. By analyzing the monitoring information of roadway deformation in Selby Coal Field in the United Kingdom, Kent [14] evaluated the influences of geological and stress changes on the anchor bolts that support the coal mine roadway and highlighted the importance of adjusting the bolt design in accordance with local conditions. Based on the investigation of the stability control of roadway surrounding rocks, the influence of the changing stress field on the stability of these rocks should be further examined.

With regard to the influence of the lateral pressure coefficient on the roadway, Niedbalsk et al. [15] analyzed geomechanics, geological structure, and roadway mining technology and stated that the design of the coal mine roadway should be evaluated from the perspective of the stress influence on roadway stability. Xu et al. [16] analyzed the effects of lateral pressure coefficient on the plastic zone distribution around a circular tunnel and stress relief by using the conformal mapping method and complex variable theory. Vazaios [17] evaluated the rupture mechanism of rock tunnels and studied the evolution law of the excavation damage zone under high-stress conditions through the finite element method. Tian et al. [18] used the ANSYS software to investigate the influence of lateral pressure coefficient on the fillet stability of a rectangular roadway and then obtained the roadway plastic zone and surrounding rock deformation characteristics under the influence of the former. The existing research studied the difficulties in roadway support due to the tectonic stress-induced variation in lateral pressure coefficient, but the variation in this coefficient due to mining disturbance and its influence on the deformation failure of mining roadways are rarely explored. The surrounding rocks are regarded as a continuous elastomer in the finite element method. The crack distribution and postcrack stress characteristics of roadway surrounding rocks cannot be observed. Therefore, the Particle Flow Code (PFC) discrete element software is utilized to study the cracks in roadway surrounding rocks at a considerably mature level [19-22].

To address the deficiencies in the existing research, the roadway of the 1131 working face in Zhujidong Coal Mine in the Huainan mining area, China was taken as the engineering background of the present study. A rectangular roadway model was established via the 2D PFC (PFC2D) software to investigate the influence of six different lateral pressure coefficients on the rectangular roadway, as well as the stress distribution laws, displacements, and crack propagation laws in the surrounding rocks at the roof, floor, and sidewalls of the roadway under such coefficients. An optimized support design plan was proposed for the mining roadway by incorporating engineering practice. The rationality of the numerical simulation model was verified through a comparative analysis with the application effect in practical engineering to provide a reference for the study on the influence laws of lateral pressure coefficient on mining roadway stability and validate the application effect of the proposed roadway support scheme.

The remainder of this study is organized as follows. Section 3 introduces the PFC numerical simulation principle, parameter determination, and model loading method. Section 4 analyzes the numerical simulation results under different lateral pressure coefficients, discusses the influence laws of this coefficient on the surrounding rock deformation, supports the parameter selection, and verifies the influence laws through practical engineering. Section 5 provides the conclusions.

\section{Methodology}

\subsection{PFC2D numerical method}

The particle flow method, which is a computing method that regards a material as a particle aggregate, was proposed by Cundall [23] in 1971 and gradually developed into the mesoanalysis software PFC. In a PFC2D model, which is formed through random disk particle aggregation, the mechanical behaviors of the particles are calculated using the explicit time step method. The adhesion among the particles in the model follows the basic theories of force-displacement law and Newton's second law, and the contact force among the particles is gradually updated via the force-displacement theorem. The model adjusts the contact relationship between the particles and the walls in accordance with Newton's second law and performs the traversal operation of each particle based on time step until the model reaches equilibrium or an unstable state due to failure. The common contact form in geotechnical engineering is divided into two types: contact and parallel adhesions. As shown in Figs. 1 and 2, the former only transfers force, whereas the latter can transfer force and moment. Therefore, contact adhesion is suitable for simulating sandy soil-type bulk granular materials, whereas parallel adhesion is ideal for simulating rock materials. This study adopts the latter. 
Zhiyu Chen, Zhiqiang Yin, Jucai Chang, Wenbao Shi and Xingqiu Peng/

Journal of Engineering Science and Technology Review 13 (5) (2020) 42 - 49

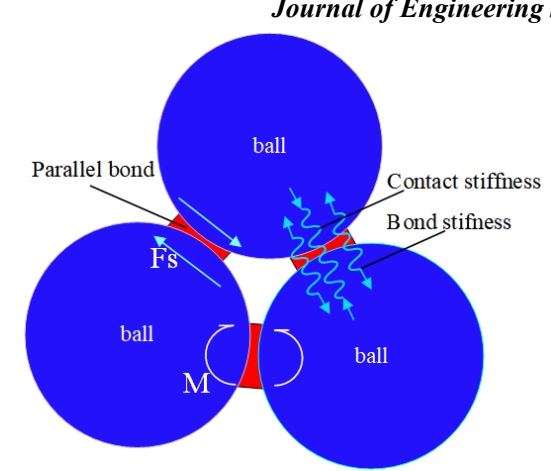

Fig. 1. Contact bond $(\mathrm{M}=0)$

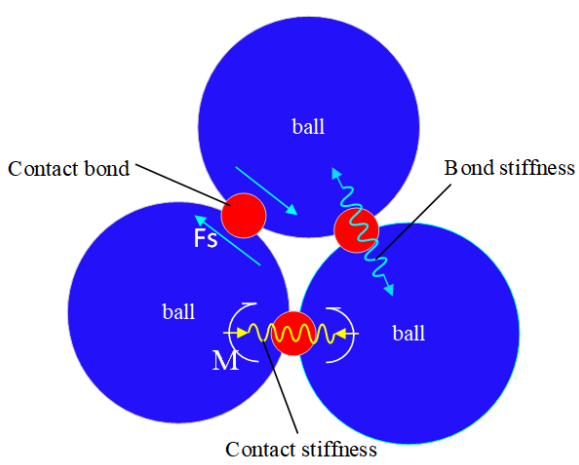

Fig. 2. Parallel bond $(\mathrm{M} \neq 0)$

\subsection{Determination of the mechanical parameters of the surrounding rock}

The mining roadway of the 1131 working face in Zhujidong Coal Mine is a nearly horizontal roadway with a rectangular cross-section. The burial depth is $930 \mathrm{~m}$, and the roof and floor have approximate lithology. The rock core was drilled on the site of roadway engineering and processed into standard specimens (Fig. 3a) in the laboratory for the rock mechanics experiment. The uniaxial compression and Brazilian split tests were performed using the RMT900 rock mechanics testing machine. The uniaxial compression failure mode of the specimen is shown in Fig. 3b, and the physical and mechanical parameters of the roadway surrounding rock are listed in Tab. 1.

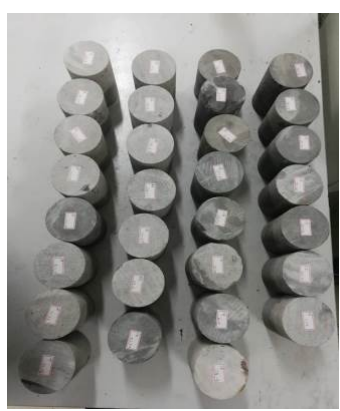

(a) Specimen

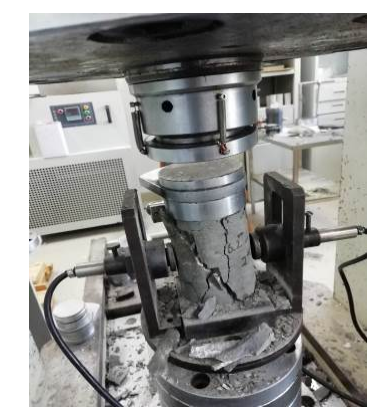

(b) Failure characteristics
Fig. 3 Uniaxial compressive test

Table 1. Physical properties of surrounding rock

\begin{tabular}{c|c}
\hline Physical parameters & Parameter values \\
\hline Rock types & Sandy mudstone \\
Deeps $(\mathrm{m})$ & 930 \\
Tensile strength $(\mathrm{MPa})$ & 2.179 \\
Compressive strength $(\mathrm{MPa})$ & 24.06 \\
Poisson's ratio & 0.17 \\
Elastic Modulus of compressive $(\mathrm{GPa})$ & 3.58 \\
Elastic Modulus of tensile $(\mathrm{GPa})$ & 3.0 \\
Internal friction angle $\left({ }^{\circ}\right)$ & 38 \\
\hline
\end{tabular}

3.3 Microparameter calibration of the model

The selected mesoparameters for the model were calibrated using the rock uniaxial test parameters. In consideration of the size restriction of the standard specimen in the laboratory and particle diameter in PFC2D, a rectangular specimen model with length and height of 4 and $8 \mathrm{~m}$, respectively, was used as the uniaxial specimen model in the parameter calibration. For the convenience of the calculation of the strain and Poisson's ratio, biaxial test at low confining pressure is adopted in the calibration.

The stress-strain curve generated through numerical simulation was obtained after the parameter calibration and compared with that generated through the uniaxial compression test (Fig. 4). Both curves were consistent in morphology, but the peak strain of the former was smaller than that of the latter because no original crack existed among the particles in the numerical model. Moreover, no crack compaction phase was observed in the obtained stressstrain curve. The experimental and numerical test failure modes of the specimen are displayed in Fig. 5. The specimen failure mode in the simulation was in good agreement with that in the uniaxial compression test. On the basis of the calibration results, simulating the rock roadway via PFC2D is reasonable. The mesoparameters of the model were obtained through calibration (Tab. 2).

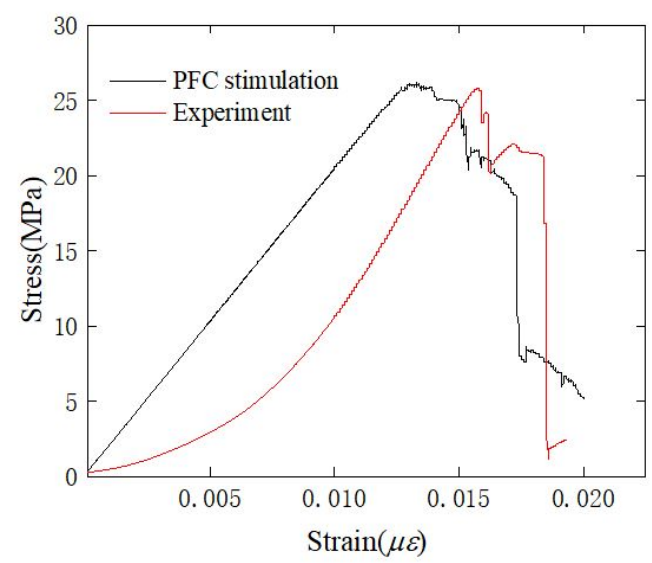

Fig. 4. Comparison of experimental and calibration result

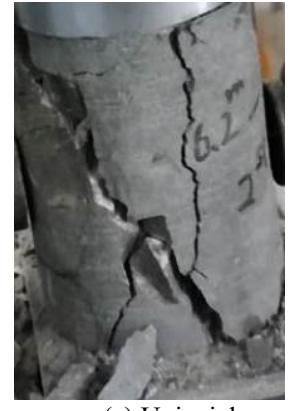

(a) Uniaxial

Fig. 5. Failure mode of specimen

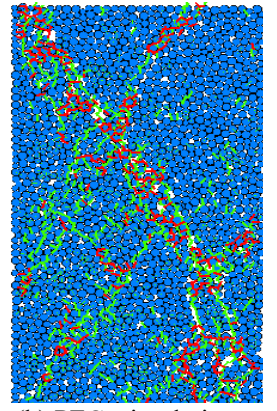

(b) PFC stimulation
Table. 2. Micromechanical parameters

\begin{tabular}{c|c}
\hline Mesoscopic parameters & Parameter values \\
\hline Density $\left(\mathrm{kg} / \mathrm{m}^{3}\right)$ & 2700 \\
Radius $(\mathrm{m})$ & $0.02-0.03$ \\
Porosity & 0.16 \\
Stiffness ratio & 0.4 \\
Particle friction coefficient & 0.5 \\
Wall friction coefficient & 0.5 \\
Linear contact modulus $(\mathrm{GPa})$ & 5.2 \\
Parallel bonding contact modulus $(\mathrm{GPa})$ & 3.85 \\
Normal bond modulus $(\mathrm{GPa})$ & 0.011 \\
Cohesion $(\mathrm{GPa})$ & 0.008 \\
Internal friction angle $\left({ }^{\circ}\right)$ & 38 \\
Damping coefficient & 0.7
\end{tabular}




\subsection{Model construction}

The size of the roadway model was $40 \mathrm{~m} \times 40 \mathrm{~m}$, and parallel adhesion was adopted as the adhesion among the particles. To achieve acceptable calculation accuracy and satisfy the research requirements, the model was constructed using particles with minimum and maximum radii of 20 and $30 \mathrm{~cm}$, respectively. Multiple preliminary experiments indicated that the stress distributions at the roadway roof and floor, as well as those at the left and right walls, were symmetrical. Therefore, 10 measuring circles were arranged only at the roof and right wall. The arrangement of the measuring circles in the model is shown in Fig. 6. The maximum horizontal distance and maximum vertical distance from the measuring circles to the free face are 11.7 $\mathrm{m}$.

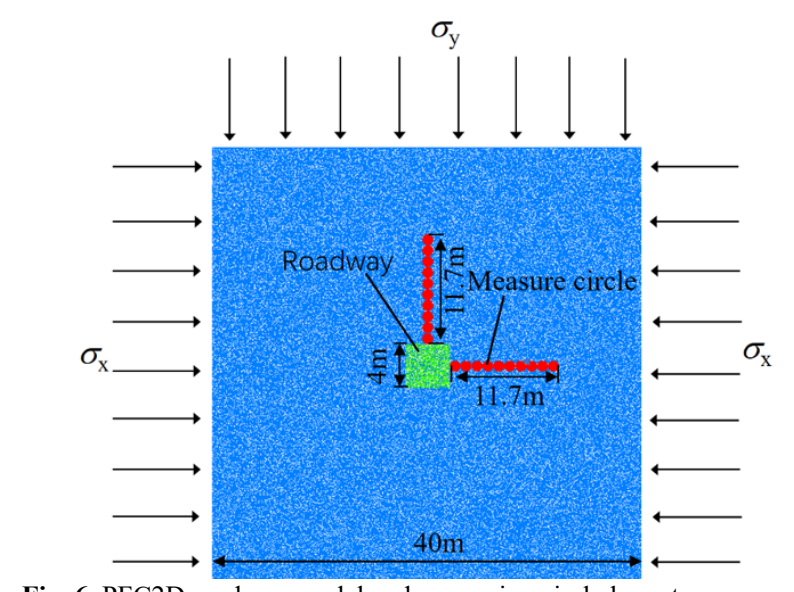

Fig. 6. $P F C 2 D$ roadway model and measuring circle layout

The calibrated mesoparameters were applied to the model during the simulation. The wall position at the bottom of the model was fixed; constant speed was applied to the top, left, and right wall bodies through the servo mechanism in PFC until the loading to the vertical and horizontal stresses set by the servo; and the measuring circles were added for the post-excavation calculation. The change laws of the lateral pressure coefficient of one section of the roadway under disturbance should be determined to select the appropriate lateral pressure coefficient for the simulation. Under the influence of mining disturbance, the lateral pressure coefficient of the mining roadway gradually increased to the maximum value (approximately 1.35 times of that under no disturbance) before declining to the minimum value (0.7 times of that under no disturbance) [3]. According to the field monitoring of the ground stress on the 1131 working face in Zhujidong Coal Mine, the lateral pressure coefficient under no disturbance was 0.95 . On the basis of the maximum and minimum values under mining disturbance, the variation range of the lateral pressure coefficient in front of the working face under mining action was $0.67-1.28$. To comprehensively investigate the stress and deformation characteristics of the roadway within this variation range, the simulation was conducted under lateral pressure coefficients of $0.4,0.6,0.8,1.0,1.2$, and 1.4.

\section{Results and Discussion}

\subsection{Stress distribution characteristics in the roadway under different lateral pressure coefficients}

The failure mode of roadway surrounding rock is divided into tensile and shear failures. The former is related to the maximum principal stress, whereas the latter frequently occurs on the plane with the maximum shear stress. The monitoring emphasis in this study was placed on the size and position of the maximum principal and shear stresses in the simulation, which are the bases for the evaluation of the failure-prone range of the roadway.

\subsubsection{Stress distribution characteristics on the roof}

The maximum principal and shear stresses of the surrounding rock at different depths on the roof of the mining roadway under different lateral pressure coefficients are presented in Figs. 7a and 7b, respectively. As the lateral pressure coefficient increases from 0.4 to 1.4 , the maximum principal stress at different depths of the roadway roof increases. The degree of increase in the shallow part is significantly greater than that in the deep part. The maximum principal stress increases from $25 \mathrm{MPa}$ to 40.3 $\mathrm{MPa}$, whereas the maximum principal stress position decreases from $10.1 \mathrm{~m}$ to $4.1 \mathrm{~m}$. When the lateral pressure coefficient is 1.4 , the maximum principal stress at the roadway edge is $0 \mathrm{MPa}$, and a maximum stress value of 61.2 $\mathrm{MPa}$ is generated at $2.9 \mathrm{~m}$ inside the roadway surrounding rock. As shown in Fig. 7b, the maximum shear stress at the shallow part of the roadway roof $(0.5 \mathrm{~m})$ increases from 0.5 $\mathrm{MPa}$ to $15.6 \mathrm{MPa}$ as the lateral pressure coefficient increases from 0.4 to 1.4. When the lateral pressure coefficient is 1.4 , the maximum shear stress at the roadway edge is $0 \mathrm{MPa}$, and a maximum stress value of $17.8 \mathrm{MPa}$ is observed at $2.9 \mathrm{~m}$ inside the surrounding rock. In summary, when the lateral pressure coefficient is large (1.4), the maximum principal and shear stresses is observed at $2.9 \mathrm{~m}$ inside the surrounding rock at the roadway roof where failure can easily occur.

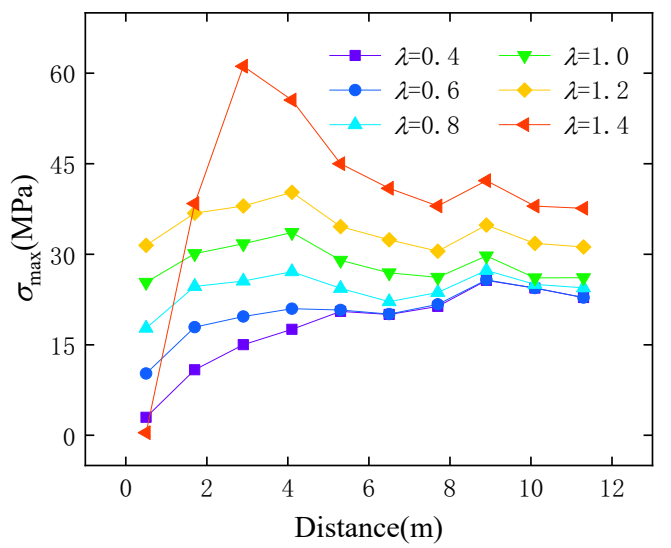

(a) Maximum principal stress

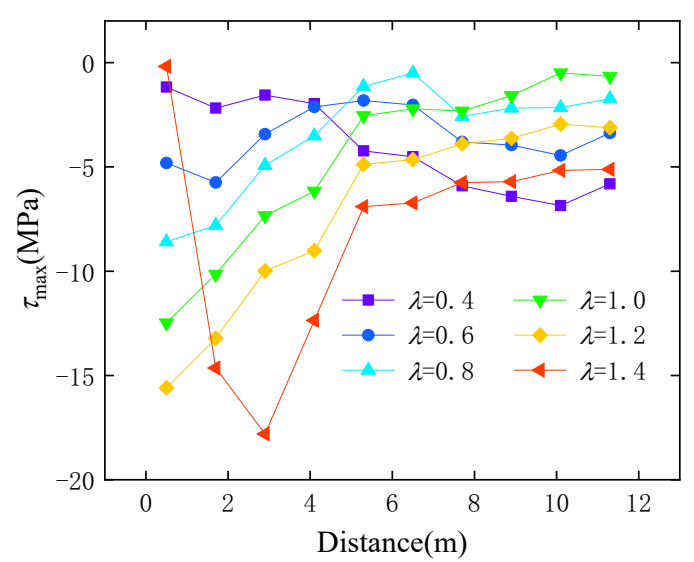

(b) Maximum shear stress

Fig. 7. Stress distribution of the roof of the roadway 


\subsubsection{Stress distribution characteristics on the roof}

The maximum principal and shear stresses of the surrounding rock at different depths on the right side of the mining roadway under different lateral pressure coefficients are shown in Figs. $8 \mathrm{a}$ and $8 \mathrm{~b}$, respectively. As the lateral pressure coefficient increases from 0.4 to 1.4 , the depth of the position of the maximum principal and shear stresses exhibits no evident change. However, the maximum principal stress at the shallow part of the roadway roof (1.7 $\mathrm{m})$ decreases from $46.2 \mathrm{MPa}$ to $35.2 \mathrm{MPa}$, and the maximum shear stress at the same position also declines from 17.2 $\mathrm{MPa}$ to $11.8 \mathrm{MPa}$. In conclusion, at small lateral pressure coefficient $(0.4)$, the maximum principal and shear stresses are high at $1.7 \mathrm{~m}$ inside the surrounding rock at sidewalls, which is an area that is prone to failure.

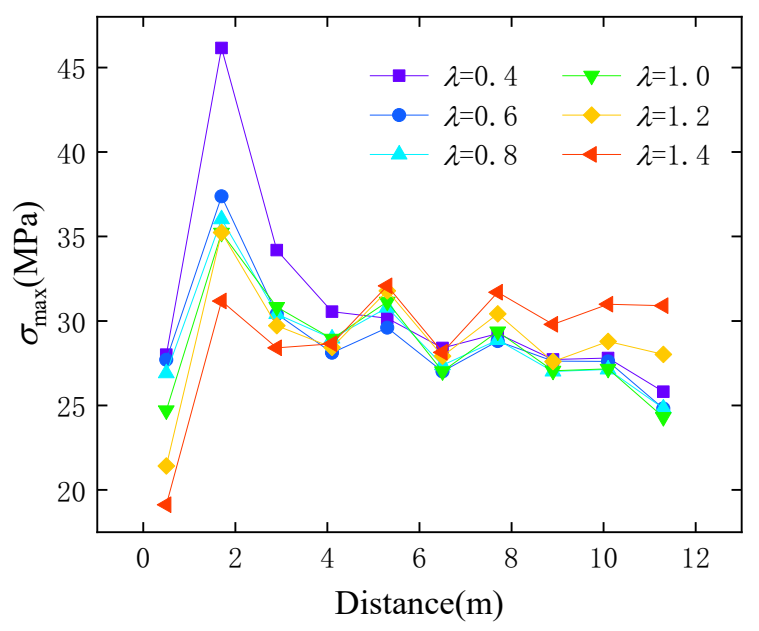

(a) Maximum principal stress

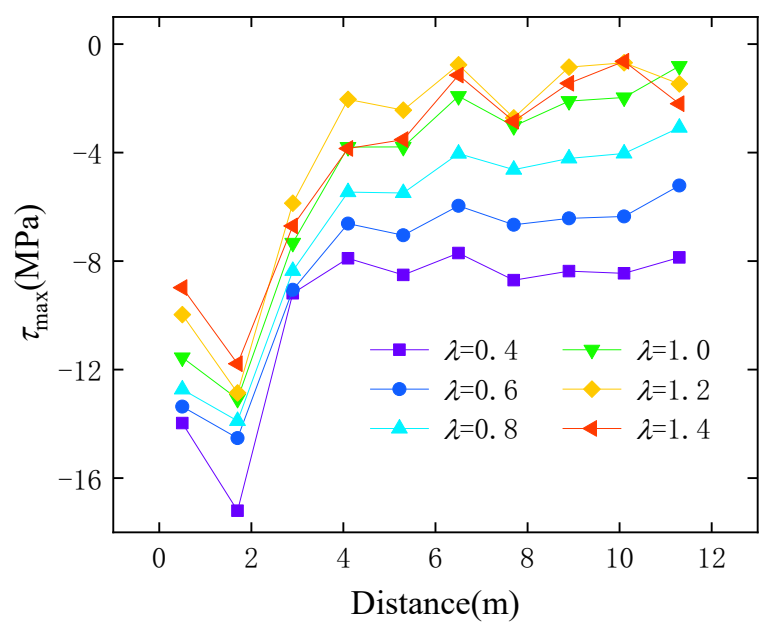

(b) Maximum shear stress

Fig. 8. Stress distribution of the right side of the roadway

4.2 Change rules of the roadway displacement under different lateral pressure coefficients

The displacement distribution nephogram of roadway surrounding rocks under different lateral pressure coefficients is presented in Fig. 9. When the lateral pressure coefficient is 0.4 , the displacements demonstrate a semielliptical distribution on the roof and floor. The maximum displacement ranges between 10 and $20 \mathrm{~mm}$, but the increase in the displacement of the middle part of the sidewalls exceeds this range (greater than $40 \mathrm{~mm}$ ). As the lateral pressure coefficient increases from 0.4 to 1.4 , the displacement and scope of displacement at the roadway roof decrease, whereas those at the sidewalls gradually increase. When the lateral pressure coefficient is 1.4 , the maximum displacement of the sidewalls ranges between 20 and $30 \mathrm{~mm}$, whereas that of the roadway roof exceeds this range (greater than $40 \mathrm{~mm}$ ). This result indicates that the sidewalls easily fail under small lateral pressure coefficients, whereas the roadway roof and floor clearly undergo caving failure under large lateral pressure coefficients. On the one hand, from the above analysis, the wall support should be strengthened when the lateral pressure coefficient is small. On the other hand, the roof support should be reinforced when the lateral pressure coefficient is large.

\subsection{Crack development characteristics in the roadway} under different lateral pressure coefficients

Fig. 10 shows the crack distribution laws in the surrounding rock of the rectangular roadway under different lateral pressure coefficients. When the lateral pressure coefficient is 0.4 , the crack development depth on the sidewalls is $2.16 \mathrm{~m}$. As the coefficient increases from 0.4 to 1.4 , the crack quantity and development depth on the sidewalls decrease, whereas those on the roadway roof increase. When the lateral pressure coefficient is 1.4 , the crack development depth on the roadway roof is $2.86 \mathrm{~m}$. Tension cracks are distributed near the surface of the roadway, whereas shear cracks are distributed in the tension crack area. This finding suggests that roadway failure is the result of tension and shear failures. On the basis of crack development characteristics, the cracks on the two sidewalls develop when the lateral pressure coefficient is small, and thus cause the failure of the walls. When the lateral pressure coefficient is large, roof and floor cracks appeared, and cause the failure of the roof of the roadway.

The effects of lateral pressure coefficient on the crack quantity of the roadway are depicted in Fig. 11. A total of 187 cracks are generated in the roadway when the lateral pressure coefficient is 0.4 , among which 129 are tensile cracks and 58 are shear cracks. As the coefficient increases from 0.4 to 1.4 , the amount of tensile and shear cracks decreases, and then increases. Eighty-two cracks are generated in the roadway when the lateral pressure coefficient is 1.2 . When the coefficient is $1.4,636$ cracks are generated; the number of tensile cracks (421) is still higher than that of shear ones (215). The result implies that the crack quantity in the roadway is greatly affected by the lateral pressure coefficient. The crack quantity around the roadway is at minimum with good stability when the lateral pressure coefficient is close to 1 . Regardless if the lateral pressure coefficient increases or decreases, cracks develop in roadway surrounding rocks and pose threats to roadway stability and support. 


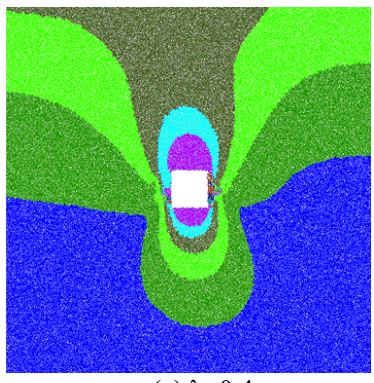

(a) $\lambda=0.4$

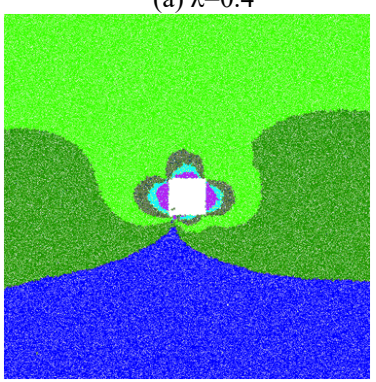

(e) $\lambda=1.2$

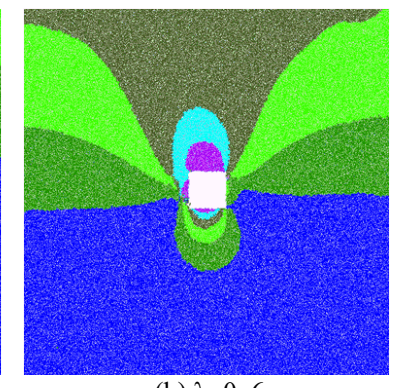

(b) $\lambda=0.6$

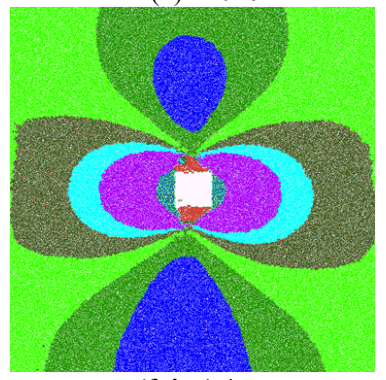

(f) $\lambda=1.4$

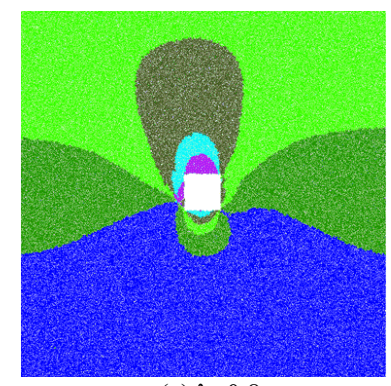

(c) $\lambda=0.8$

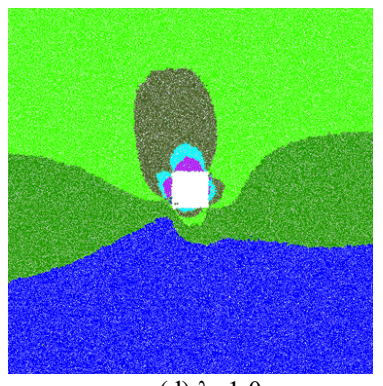

(d) $\lambda=1.0$

Fig. 9. Displacement distribution nephogram under different lateral pressure coefficients

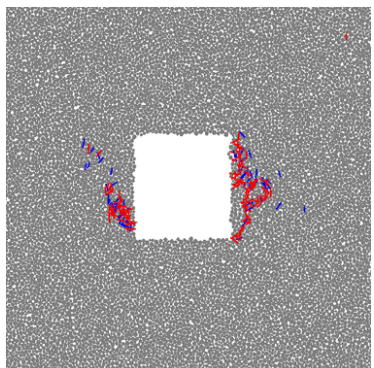

(a) $\lambda=0.4$

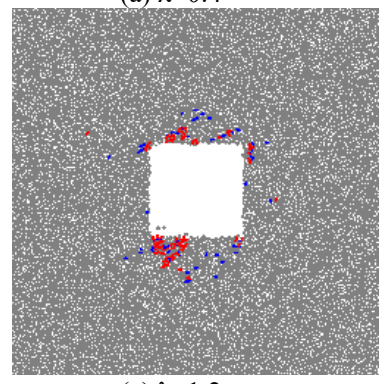

(e) $\lambda=1.2$

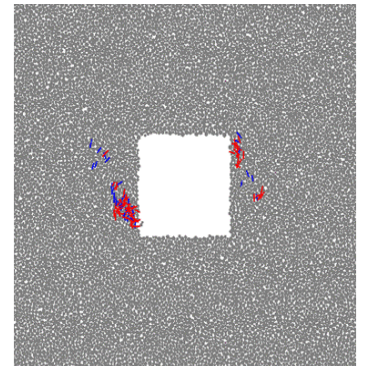

(b) $\lambda=0.6$

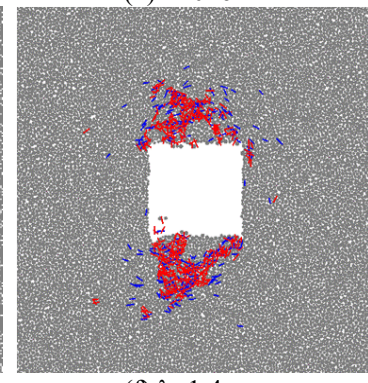

(f) $\lambda=1.4$

Fig. 10. Fracture distribution under different lateral pressure coefficients

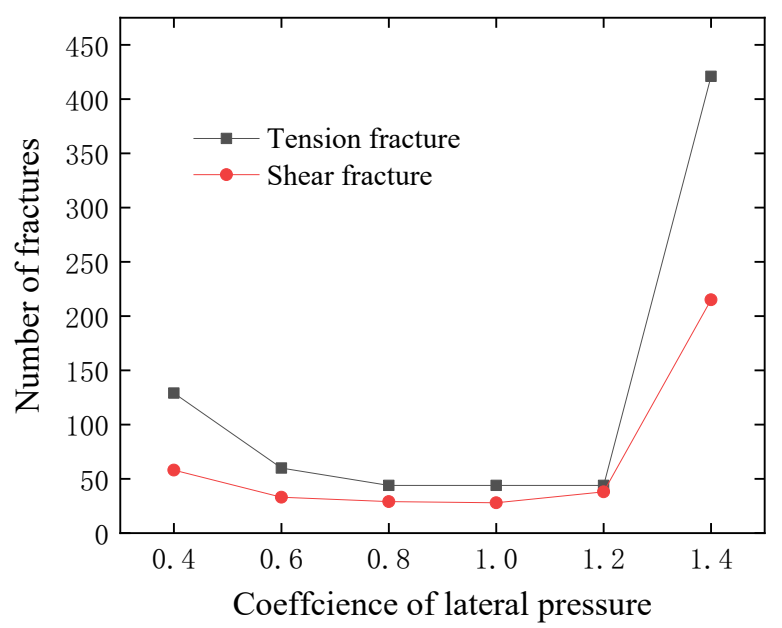

Fig. 11. Distribution of the number of fractures under different lateral pressure coefficients

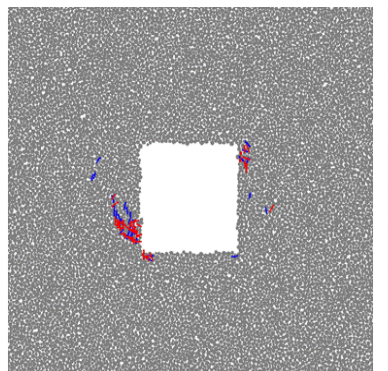

(c) $\lambda=0.8$

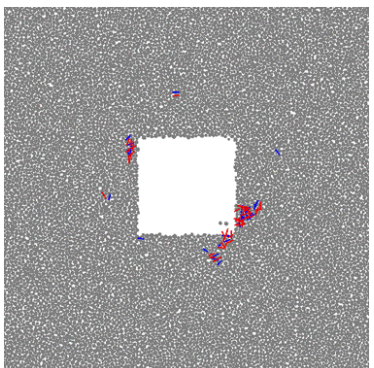

(d) $\lambda=1.0$
Tension fracture

Shear fracture

\subsection{Rectangular roadway support technology under different lateral pressure coefficients}

The bolt-mesh-cable coupling support is adopted for the initial roadway support method of the 1131 working face of Zhujidong Coal Mine. Four bolts $(\Phi 20 \times 2200 \mathrm{~mm})$ are arranged per section in the roof and sidewall of the roadway at intervals of $1 \mathrm{~m}$. Similarly, two cables $(\Phi 17.8 \times 6300 \mathrm{~mm})$ are arranged per section in the roof of the roadway at intervals of $2 \mathrm{~m}$ (Fig. 12a). The deformation of the roadway affected by mining stress is shown in Fig. 12b. The sidewall of the roadway does not exhibit significant deformation, whereas the roof does.

The roadway lateral pressure coefficient when no mining effect is present is approximately 1 . The simulation results reveal that the maximum principal $(33.6 \mathrm{MPa})$ and shear $(12.5 \mathrm{MPa})$ stresses respectively appear at 4.1 and $0.5 \mathrm{~m}$ above the roof of the roadway. Similarly, the maximum values of the two stresses ( 35.2 and $13.1 \mathrm{MPa}$, respectively) are observed at $2 \mathrm{~m}$ of the roadway sidewall. Meanwhile, the 
crack development depths on the roof and sidewall are 1.45 and $1.52 \mathrm{~m}$, respectively. In summary, when the lateral pressure coefficient is 1 , the $2.0 \mathrm{~m}$ range inside the roof and sidewall of the surrounding rock is prone to failure. Therefore, the original roadway support scheme (with support depth of $2.2 \mathrm{~m}$ ), which is not affected by mining stress, can provide a stable support to the roof and sidewall of the roadway.

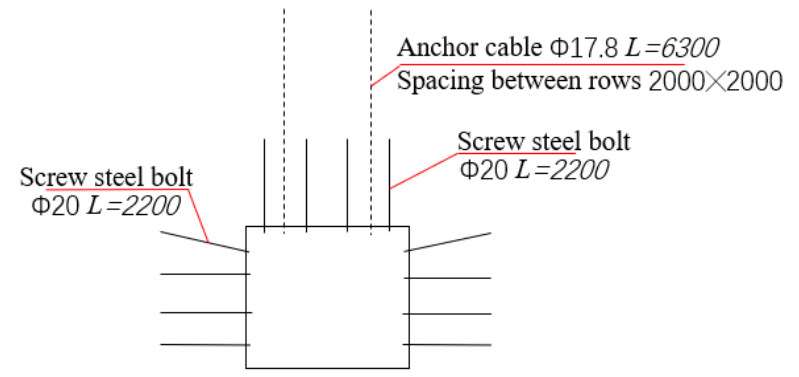

(a) Origin support method

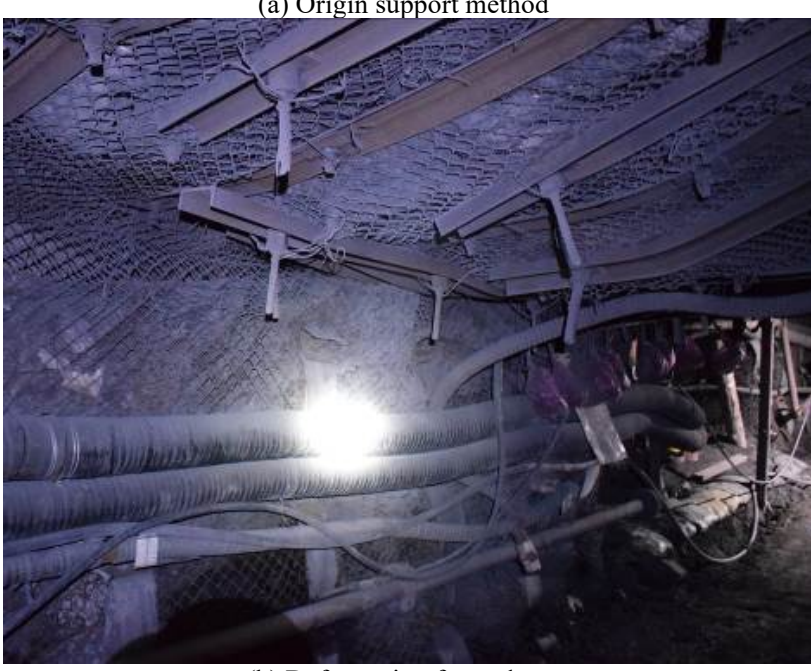

(b) Deformation fo roadway

Fig. 12. Origin support method and roadway deformation of Zhujidong mine

Given the influence of mining activities, the lateral pressure coefficient of the roadway in the 1131 working face of Zhujidong Coal Mine increased from 1 to 1.28 and then decreases to 0.67 . To ensure the stability of roadway support, the safety factor is set 1.1. The maximum and minimum lateral pressure coefficients of the roadway are 1.4 and 0.6 , respectively. As shown in Figs. 7 and 8 , when the lateral pressure coefficient increases to 1.4 , the maximum principal $(61.2 \mathrm{MPa})$ and shear $(17.8 \mathrm{MPa})$ stresses appear at $2.9 \mathrm{~m}$ above the roof of the roadway, and the cracks are quite developed. When the coefficient decreases to 0.6 , the maximum principal $(35.2 \mathrm{MPa})$ and shear $(13.9 \mathrm{MPa})$ stresses are observed at 2.0 and $1.7 \mathrm{~m}$ above the sidewall of the roadway, respectively, and the cracks are quite developed at $2.12 \mathrm{~m}$. During the mining process, cracks occur at 2.9 and $2.12 \mathrm{~m}$ on the roof and sidewall of the roadway, respectively. Given this condition, the original support method (with bolt support depth at the sidewall and roof of $2.2 \mathrm{~m}$ ) cannot provide sufficient support under varying lateral pressure coefficients. Therefore, the improved support method is proposed. Four bolts $(\Phi 20 \times$ $3000 \mathrm{~mm})$ and three cables $(\Phi 17.8 \times 6300 \mathrm{~mm}$ are arranged per section in the roof the roadway at intervals of $1 \mathrm{~m}$. The sidewall support is improved using bolts with diameter of 20 $\mathrm{mm}$ and length of 2,500 $\mathrm{mm}$. The improved support method is illustrated in Fig. 13a. After applying the improved roadway support scheme, the deformation at the roof and sidewalls is minimized, and the fracture phenomenon of the bolt is reduced. The field support effect of the roadway is shown in Fig. 13b. The sidewalls and roof are wellcontrolled, and no failure accident occurs during the mining process.
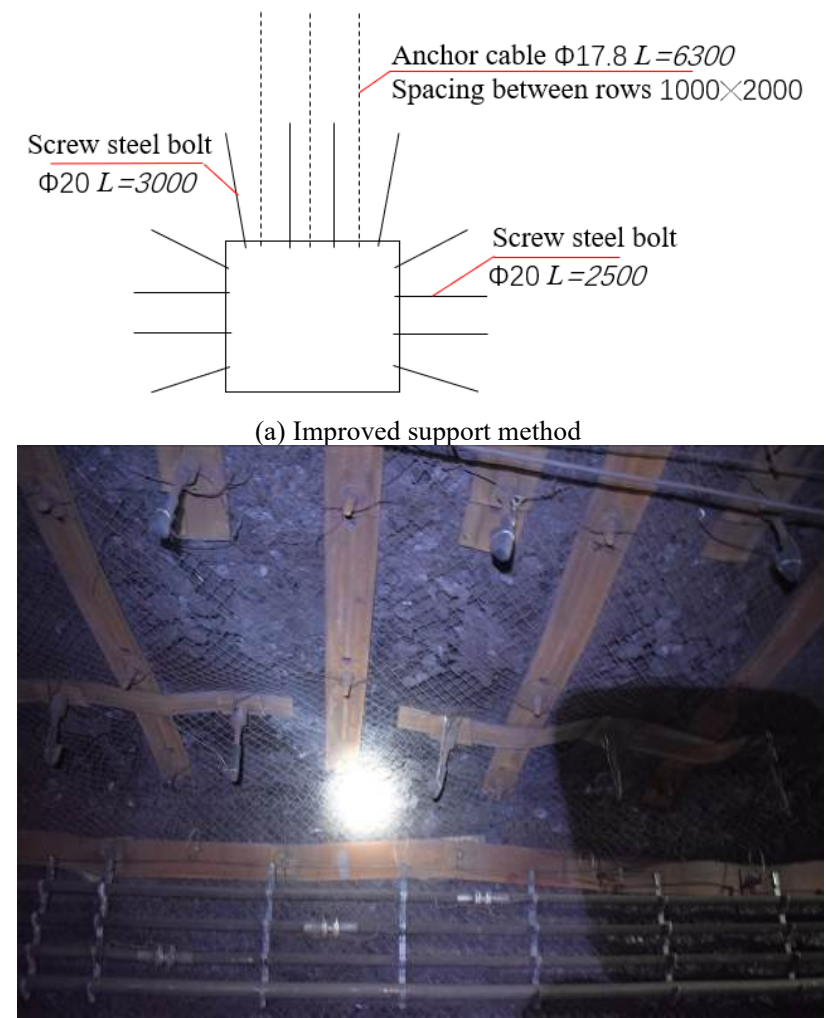

(b) Deformation fo roadway

Fig. 13. Improved support method and deformation of Zhujidong mine

\section{Conclusions}

A simulation calculation model is constructed based on the PFC discrete element method to study the stress distribution rules and failure characteristics of roadways due to the change in the horizontal stress in deep mines. The stress distribution rules (for the maximum principal and shear stresses), fracture, and displacement characteristics of the surrounding rock at the roof and sidewalls of the roadway are analyzed. This study combines the onsite monitoring of the roadway with the result of the theoretical analysis to improve the original support approach. The following conclusions are drawn.

(1) As the lateral pressure coefficient increases from 0.4 to 1.4 , the maximum principal and shear stresses at the roof increase, whereas those at the sidewall decrease. When the lateral pressure coefficient is 1.4, the values of the two stresses at $2.9 \mathrm{~m}$ inside the surrounding rock of the roadway roof are 61.2 and $17.8 \mathrm{MPa}$, respectively. When the lateral pressure coefficient is 0.4 , their values at $1.7 \mathrm{~m}$ inside the surrounding rock of the roadway sidewall are 46.2 and 17.2 $\mathrm{MPa}$, respectively.

(2) As the lateral pressure coefficient increases from 0.4 to 1.4 , the scope and amount of displacement and at the roof increase, whereas those at the sidewall decrease. The maximum displacement amount is obtained in the displacement superposition zone at the roof or sidewalls. 
With the increase in this coefficient, the crack quantity and development depth at the sidewalls decrease, whereas that at the roof increase. The maximum crack development depths on the roadway sidewalls and roof are 2.16 and $2.86 \mathrm{~m}$, respectively.

(3) The numerical simulation results reveal that when the lateral pressure coefficient of the roadway is changed by the mining process, the failure depths at the sidewall and roof are 2,120 and 2,900 $\mathrm{mm}$, respectively. In addition, the length of the bolt in the original support method increases from 2, $200 \mathrm{~mm}$ to 2,500 and $3,000 \mathrm{~mm}$, respectively. A cable is then added to the roof to reinforce the support. The optimized support method based on the numerical results significantly reduces the surrounding rock deformation and relieves the fracture of the bolts. Moreover, no deformation instability accident happens in the roadway.

In this study, the discrete element simulation of rectangular roadways under different lateral pressure coefficients is assumed to be unaffected by the geological structure. However, the boundary conditions may require further optimization under the influence of such structure in other engineering fields. Therefore, further studies are necessary to determine the accurate influence of the geological structure on the lateral pressure coefficient and optimize the support for the mining roadways of deep mines.

\section{Acknowledgements}

The authors are grateful for the support provided by the National Natural Science Foundation of China (51874006 and 51774009) and Anhui Provincial Natural Science Foundation (1808085ME134).

This is an Open Access article distributed under the terms of the Creative Commons Attribution License

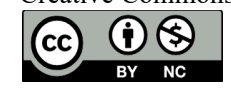

\section{References}

1. Singh, P., Spearing, A. J., Jessu, K. V., Ribeiro, P. C., "Establishing the need to model the actual state of stress along rock bolts". International Journal of Mining Science and Technology, 30(3), 2020, pp.279-286.

2. Forbes, B., Vlachopoulos, N., Hyett, A. J., Diederichs, M. S. "A new optical sensing technique for monitoring shear of rock bolts". Tunnelling and Underground Space Technology, 66, 2017, pp.34-46.

3. Guo, Y., Zhou, H., Rong, T., Wang, L., Zhong, J., Ren, W., Chen, J., "Disturbance characteristics of deep coal body under mining stress path". Journal of China Coal Society, 43(11), 2018, pp.3072-3079. (in Chinese)

4. Meng, Y., Xue, S., Wang, R., Deng, X., "Acoustic method based on integrity coefficient for testing the loose circle of surrounding rock". Journal of Highway and Transportation Research and Development, 12(2), 2018, pp.67-72.

5. Guo, X., Zhao, Z., Gao, X., Wu, X., Ma, N., "Analytical solutions for characteristic radii of circular roadway surrounding rock plastic zone and their application". International Journal of Mining Science and Technology, 29(02), 2019, pp.263-272.

6. Kong X.X., Liu Q.S., Zhang Q.B., Wu Y.X., Zhao J., “A method to estimate the pressure arch formation above underground excavation in rock mass". Tunnelling and Underground Space Technology, 71, 2018, pp.382-390.

7. Li, C., Zhang, W., Wang, N., He, C., "Roof stability control based on the evolution of plastic zone under the influence of mining". Journal of Mining and Safety Engineering. 36(4), 2019, pp.753761. (in Chinese)

8. Waclawik, P., Kukutsch, R., Konicek, P., Ptacek, J., Kajzar, V., Nemcik, J., Vavro, M., "Stress state monitoring in the surroundings of the roadway ahead of longwall mining". Procedia Engineering, 191, 2017, pp.560-567.

9. Khalymendyk, I., Baryshnikov, A., "The mechanism of roadway deformation in conditions of laminated rocks". Journal of Sustainable Mining, 17(2), 2018, pp.2300-3960

10. Frith, R., Reed, G., Mckinnon, M., "Fundamental principles of an effective reinforcing roof bolting strategy in horizontally layered roof strata and areas of potential improvement". International Journal of Mining Science and Technology, 28(1), 2017, pp.6777.

11. Li, T., Lu, Z., Liu, J., Ma, X., "Deformation and failure process analysis of rectangular roadway in muddy weakly cemented soft rock strata". Rock and Soil Mechanics, 35(04), 2014, pp.10771083. (in Chinese)
12. Gong, F., Wu, W., Li, T., Si, X., "Experimental simulation and investigation of spalling failure of rectangular tunnel under different three-dimensional stress states". International Journal of Rock Mechanics and Mining Sciences, 122, 2019, pp.104081.

13. Mark, C., "Coal bursts that occur during development: A rock mechanics enigma". International Journal of Mining Science and Technology, 28(1), 2017, pp.35-42.

14. Kent, F. L., Coggan, J., Altounyan, P. F., "Investigation into factors affecting roadway deformation in the selby coalfield". Geotechnical and Geological Engineering, 16(4), 1998, pp.273289.

15. Niedbalski, Z., Majcherczyk, T., "Indicative assessment of design efficiency of mining roadways". Journal of Sustainable Mining, 17(3), 2018, pp.131-138.

16. Xu, M., Wu, S., Gao, Y., Ma, J., Wu, Q., “Analytical elastic stress solution and plastic zone estimation for a pressure-relief circular tunnel using complex variable methods". Tunnelling and Underground Space Technology, 2019, pp.381-398.

17. Vazaios, I., Vlachopoulos, N., Diederichs, M. S., “Assessing fracturing mechanisms and evolution of excavation damaged zone of tunnels in interlocked rock masses at high stresses using a finite-discrete element approach". Journal of Rock Mechanics and Geotechnical Engineering, 11(4), 2019, pp.701-722.

18. Tian, J., Song, H., "Influence of lateral pressure coefficient on stability of rectangular roadway with fillet". Safety in Coal Mines, 45(7), 2014, pp.195-197. (in Chinese)

19. Gutiérrez-Ch, J.G., Senent, S., Melentijevic, S., Jimenez, R., "Distinct element method simulations of rock-concrete interfaces under different boundary conditions". Engineering Geology, 240, 2018, pp.123-139.

20. Ozturk, H., Guner, D., "Laboratory and distinct element analysis of the deformability behaviour of thin spray-on liners", International Journal of Rock Mechanics and Mining Sciences, 123, 2019, pp.1365-1609.

21. Lin, B., Liu, T., Zou, Q., Zhu, C., Yan, F., Zhang, Z., "Crack propagation patterns and energy evolution rules of coal within slotting disturbed zone under various lateral pressure coefficients". Arabian Journal of Geosciences, 8(9), 2015, pp.6643-6654.

22. Bai, Q., Tu, S., Zhang, C., Zhu, D., "Discrete element modeling of progressive failure in a wide coal roadway from water-rich roofs". International Journal of Coal Geology, 167, 2016, pp.215-229.

23. Zhou, L., Yang, B., "Simulation of a hot-rolled h-section steel beam subject to static loading based on discrete element method". Procedia Engineering, 210, 2017, pp.312-319. 